\title{
THE IMPACT OF TEACHERS' LINGUISTIC AND AFFECTIVE FEEDBACK ON IRANIAN EFL STUDENTS' WRITING SKILLS
}

\author{
Ali Safivand ${ }^{1}$, Reza Vahdani Sanavi ${ }^{2}$, Abdolvahab Khademi-Shamami $^{3}$ \\ ${ }^{1}$ Islamic Azad University - Shahre Qhods Branch (IRAN, ISLAMIC REPUBLIC OF) \\ ${ }^{2}$ Islamic Azad University - Roudehen Branch (IRAN, ISLAMIC REPUBLIC OF) \\ ${ }^{3}$ Iran University of Science \& Technology (IRAN, ISLAMIC REPUBLIC OF) \\ ali.safivand@gmail.com, vahdani.reza@gmail.com, vahab.khademi@gmail.com
}

\begin{abstract}
Errors and error correction are two basic elements of an EFL writing class, and Iranian EFL teachers have always been grappling with the students' mistakes and errors. Tracking down applicable techniques and efficient strategies for correcting students' mistakes and errors has forced teachers to carefully scrutinize the students' behaviour, skills, aptitudes, and the conditions of the class. On the other hand, one of the students' needs in EFL writing courses is a clear assessment of their progress. Therefore, teachers may have to respond and comment on the students' progress according to their performance. This study was an attempt to investigate the impact of teachers' feedback and comments on EFL students' writing skill improvement. To answer this question, a one-way Analysis of Variance (ANOVA) was carried out and the results confirmed the existence of a significant effect of teachers' feedback and comments on EFL students' writing. Students were motivated to write more creatively and at the same time they had more improvement in the writing skill. The findings based on the reports given by the teachers also suggest that students' negative attitude toward writing perceived as a boring, difficult, time consuming, and unimportant task gradually leaned toward a positive one.
\end{abstract}

Keywords: Comment, Composition, EFL, Essay, Expectation, Expository writing, Feedback, Mechanics, Pre-test, Post-test, Rater, Score.

\section{INTRODUCTION}

Writing has always been referred to as the most difficult, boring, and complicated skill among the four language skills by the language learners, especially when learning and teaching of writing and correcting errors are concerned. Based on the humanistic approach, if the learners do not involve themselves in learning and in the way learning takes place, then some of the teaching methods and techniques may be of no use for facilitating learning. Therefore, teachers, by putting into practice their experience and knowledge in order to adopt workable methods and techniques, can ameliorate conditions for students to develop their writing abilities successfully. Brown [1] states, "a section on scoring and grading would not be complete without some feedback that you want to become beneficial washback" (p. 62). He also added that achieving washback is possible when students can identify the testing experience through their success and challenge areas. Hence, teachers can have a key role in improving the students' learning process. They can teach the structures of the English language, mechanics of writing, paragraph writing, essay writing, and other elements of writing skills. In addition, teachers can let the students become acquainted with various styles of writing. Each session they can assign some writing exercises to students and correct the students' previous writing tasks. Then having corrected the students' writing tasks, teachers can help students be aware of their errors and mistakes via providing them with proper feedback and comments.

Iranian EFL teachers, also, have always strived to motivate students to develop their writing skills through correcting the students' writings and providing them with linguistic feedback. Their attempts, however, can be exerted directly or indirectly, as one of the students' needs in EFL writing courses is a clear assessment of their progress. Nonetheless, frequent and selective assessments, from the teachers, provide students with objective, straightforward, and precise comments about their success and progress.

Based on the above mentioned factors, teachers may respond to and comment on the students' progress according to their performance. In this study, the researchers aimed at finding the impact of teachers' linguistic and affective feedback on students' writing skills. This research was designed in 
an attempt to find a way to change the negative attitude of students towards writing tasks via providing them with suitable feedback and comments.

Therefore, the main goal of the researchers was to help the teachers, one of whose main goals is paving the way for students to get the best results from the English courses, act or behave with more consideration toward their students and their progress. The researchers also believe that informing students, to some extent, may help them to sustain their achievement.

\section{THE REVIEW OF THE RELATED LITERATURE}

Cohen, Cohen and Cavalcanti, Radeckit and Swales (as cited in Raimes [2]), all assert that in order to find out students' responses, researchers are looking at students' responses to feedback, so they can mainly find that students can simply make a mental note of teachers' response.

Moreover, Raimes [2] believes that teachers can correct, code, locate, and indicate the number of errors. Teachers can also comment on form, make generalized comments about content (such as; "good description" or "odd details"), make text-specific comments (such as; "I'm wondering here what Carver tells the readers about children"), ask questions, make suggestions, emote with comments (such as; "nice", "excellent", or "I'm bored"), praise, and ask students to comment on the source of the error.

Furthermore, teachers, by responding to and commenting on students' writings, inadvertently communicate their expectations about the students' performance which seems to relate to the students' achievement. Ryan and Cooper [3] believe, 'the source of the teachers' expectations may vary with students' social class, race, or sex; information from previous teachers; test scores; or family background information" (p. 75). Therefore, the comments and the feedback the teachers give their students during the term let the students find out how they are supposed to improve their writing skills and to fulfil the teachers' expectations.

Vigil and Oller [4] asserted that feedback can be of two major types - affective and cognitive feedback - and each type can be positive, negative, or neutral. Affective information is usually encoded in terms of kinesics mechanisms, such as gestures, tone of voice, and facial expressions.

Cognitive information is usually conveyed by means of linguistic devices such as sounds, phrases, structures, and discourse.

Affective feedback can be positive ("I like it", "I enjoyed a lot", and etc.), neutral "waiting..." (reaction undecided), or negative "I don't like it"(try something else).

Cognitive feedback can be positive "I understand" (message and direction are clear), neutral "still processing..."(undecided), or negative "I don't understand" (message and/or direction are not clear).

Zamel (as cited in Nunan [5]) states, "the writing class should take into account the learners' purposes for writing which transcend that of producing texts for teacher evaluation. Writing skills can develop rapidly when students' concerns and interests are acknowledged, when they are given numerous opportunities to write, and when they are encouraged to become participants in a community of writers." Zamel explains more and suggests that by engaging in types of inquiry and investigation teachers can apply insights from what they have learned in the most profound way. On the other hand, Lewis [6] contended that the meaning of writing in a new language is broader and wider in comparison to translating or doing exercises from a textbook. Also, depending on how far one might take his/her language studies, s/he could, as in her/his first language, write everything from formal letters or informal messages on the e-mail to creative writing.

Bowen, Madsen, and Hilferty [7] considered writing as more an individual effort than speaking. Writing is more rule-bound and therefore more error-prone. Writing requires the selection of the most appropriate forms to express exactly one wishes to say. Chastain [8] believes that expressing one's thoughts in writing is tough even if it is under the most appropriate and natural circumstances.

On the other hand, Lewis [6] believes, "In writing there is less cooperation. You send away a written message and the other person can ignore it or take time to answer" (p. 34). He also explains more about the difference between speaking and writing skills and says:

In speech the context helps in making sense of what people are saying. This can be a trap when you are talking to people who have a different background from yours. It is easy to assume that everyone knows what you mean. In writing, on the other hand, 
people spell things out more. Instead of using phrases such as 'like this' or 'over there' they substitute words that have meaning. (p. 33)

According to Luria [9] the relationship between writing and speaking is a little bit complicated. The writing process starts with a breaking down of spoken word into its single sounds whose phonemic importance has been clarified, where the phonemes are represented by letters that are integrated to produce a written word. However, according to Coltheart [10] in most languages, such as English and French, there is no isomorphism between phonemes and letters, so the simple mapping of phonemes onto letters would produce uncharacteristically inaccurate spelling; normal, correct spelling in such languages cannot be quite dependent on spoken word production.

On the other hand, according to Ellis [11] it is possible that spelling may be assisted by speech, e.g. German language. Writing words based on Dual-route models of writing involves the activation of an abstract, orthographic entry in a Graphemic Output Lexicon (GOL). The activated graphemic representation is placed in a Graphemic Output Buffer (GOB) where it awaits further allographic and motoric processing. The writing of non-words, however, involves a Phoneme-to-Grapheme Conversion (PGC) system which maps phonological segments onto graphemic forms which enter onto the GOB and are further processed in the normal way.

Reid (as cited in Raimes [12]), mentioned that textual features, like the number of passives or the number of pronouns, are counted and compared for uses of various cultures. Researchers have examined the structure of such features as introductory paragraphs, the form of essays in different languages, cohesion, and coherence, and topical structure. A form-dominated approach has the largest body of research to inform and support it. Old concerns were replaced by the new. Instead of "accuracy" and "patterns", "process", "making meaning", "invention", and "multiple drafts" were substituted, and the attention to the writer as language learner and creator of text has led to a "process approach". Teachers had to allow their students time and opportunity for selecting topics, generating ideas writing drafts and revision, and providing feedback. During the time the focus from the processes of writer shifted to content and to the demands of the academy. So by 1986 a process approach was being included among "traditional approach" and in its place was proposed a "contentbased approach. With a content-based approach students are said to get help with the language of the thinking processes and the structure or shape of content. The main emphasis in this approach is on the instructor's determination of what academic content is most appropriate in order to build whole course or modules of reading and writing task around the content.

Furthermore, along with content-based approaches another academically oriented approach, English for Academic Purposes (EAP), which focuses on the expectations of academic readers came into existence. In this approach, the ESL teachers run a theme-based class, not necessarily linked to content course. A reader-dominated approach, unlike a writer dominated process approach that favors personal writing, perceives language teaching as socialization into the academic community not as humanistic therapy. Nathan [13], on the other hand, has quoted from Silvia that ESL writers need to be respected by their ESL writing teachers in four important ways. Students should be (a) understood as student writers, (b) provided suitable learning contexts, (c) provided appropriate instruction, and (d) evaluated fairly.

Farhady et al. (1996) [14] referred to free writing as the most face-valid test of writing, and writing compositions is preferred over other test procedures because of two reasons:

1. Writing compositions provides the testees with an opportunity to show their ability to organize and communicate their own ideas, using their own vocabulary, register, and style.

2. Since the testees actually write, composition tests motivate them to improve their writing skills.

Mantello [15] referred to error correction as one of the most frustrating tasks in L2. Based on her point of view, L2 instructors spend a lot of time correcting the students' errors; however, the errors are seen again recurring in students writing. Consequently, there is always a nagging feeling that teachers are correcting the same errors over and over again.

Hendrickson (as cited in Mckay [16]), stated:

If a learner understands and uses the rules correctly, he or she will produce utterances that are meaningful, grammatical, and appropriate. If a learner's hypotheses of the language rules are occasionally incorrect, however, some of his or her utterances will 
contain errors of varying types and frequencies. It is virtually impossible to avoid errors when learning any new skill, particularly when learning a foreign language. (p. 145)

Hendrickson (as cited in Mckay [16]) believed that most of the adult learners, in formal situations like classrooms and in self-study courses, are often quite conscious of their errors. For these adults, whom Krashen calls 'monitor-users' errors correction helps to discover the grammatical functions and limitations of language structures and lexical forms they are studying. In other words, error correction in the adult foreign language classroom helps many learners become aware of exact environment for using grammatical rules and for discovering the precise semantic range of lexical items.

What is more, Lapkin and Swain (as cited in Mantello [15]) believed that although there is a great frequency of both errors and error correction in second language teaching, just a little is known about the effects of error correction. Zamel (as citedby Mantello [15]), concluded that on balance, teachers' error correction practices tend to be random and arbitrary instead of being according to a clear and focused strategy. In this respect, Cardell and Carno (as cited in Mantello [15]) believed that the error correction type used by L2 educators is scarcely selected according to cognitive psychological theory. Leki (as cited in Mantello [15]) also mentioned that language learners are concerned about the errors they make and want their teachers to correct all of their errors. However, many studies point to the ineffectiveness of error correction. In other words, neither does making errors on learners' papers help them improve their writing nor eliminate their errors. As a result, Mantello [15] urged teachers to reflect on what it is that they correct errors in the first place. It is also a good idea to keep in mind that the only true objective in error correction is facilitating student learning. For selecting an error correction strategy, teachers might consider incorporating some elements such as:

- problem solving

- individualized feedback based on L2 proficiency levels

- explicit feedback for weaker learners

- applying a variety of methods, specifically for stronger students

- concentrating on a limited number of essential structures

On the other hand, Kroll and Schafer (as cited in Mckay [16]) asserted, "Specifically, the composition teacher as error analyst investigates error (to discover how a student arrived at the mistake) and then applies these insights (to help the student move further toward the target form)" (p. 137).

Mckay [16] asserted that teachers of composition often commiserate over the task of correcting papers. Robinett (as cited in Mckay [16]) also believed that correcting or grading compositions often demonstrates a dilemma to both teacher and student.

What is more, Kroll and Schafer (as cited in Mckay [16], asserted:

Although there have been several influential approaches to error in the ESL field, there has been a general movement from approaches emphasizing the product ( the error itself) to approaches focusing on the underlying process (why the error was made). At the product end the spectrum, many teachers simply corrected individual errors as they occurred, with little attempt to see patterns of errors or to seek causes in anything other than learner ignorance. (p. 135)

Mckay [16] claimed that composition teachers before correcting papers need to clarify their standards for evaluating them. A well written essay demonstrates quality on various levels including such things as knowledge of the subject, awareness of the audience, clarity of organization, richness of details, vividness of language, and accuracy of grammatical rules.

\subsection{Responding to students' writing}

\section{Sommers, (as cited in Mckay [16]), pointed out:}

More than any other enterprise in the teaching of writing, responding to and commenting on student writing consumes the largest proportion of our time. Most teachers estimate that it takes them at least 20 to 40 minutes to comment on an individual student paper, and those 20 to 40 minutes times 20 students per class, times 8 paper, more or less, during the course of a semester add up to an enormous amount time. With so much time and energy directed to a single activity, it is important for us to understand the nature of the enterprise. For it seems, paradoxically enough, that although commenting on student writing is the most widely used method for responding to student writing, it is the least understood. We do not know in any definitive way that constitutes thoughtful commentary 
or what effect, if any, our comments have on helping our students become more effective writers.

Theoretically, at least, we know that we comment on our students' writing for the same reasons professional editors comment on the work of professional writers or for the same reasons we ask our colleagues to read and respond to our own writing. [...] In commenting our students' writing, however, we have an additional pedagogical purpose. As teachers, we know that most students find it difficult to imagine a reader's response in advance, and to use such responses as a guide in composing. Thus, we comment on student writing to dramatize the presence of a reader, to help our students to become that questioning reader themselves, because, ultimately, we believe that becoming such a reader will help them to evaluate what they have written and develop control over their writing. (p. 160)

On the other hand, Mayers [17] mentions, " since the process approach to composition studies has come to replace the older tradition 'product' rhetoric that focused on correctness, the teaching of writing has incorporated invention techniques." According to Myers [17], students more than 20 years ago often produce stultifying text in response to the directions imposed upon them by their textbooks. Most of these directions were according to prescriptive grammar instruction, literary criticism and an oral rhetoric stretching back to the time of Aristotle. Instruction was not completely based on the psychological writing processes, but rather on an analysis of texts after they were produced (products). In its extreme from early on, the process approach led some of the teachers to give their students free writing and personal narration assignments uncluttered with the demands of error correction or formal register.

Moreover, Conrad and Goldstein [18] surveyed the relationship of teacher-written comments and students' subsequent revisions and the results showed that only one feature typically was related to revision success of the students and it was the type of revision problem that was addressed. However, the students were not successful in revising problems concerning explanation, explicitness, and analysis.

Furthermore, Lee and Schallert [19] via using a case study approach explored the role of the teacherstudent relationship in how a teacher made written comments on students' writing and in how students responded to these comments in revision. The results of the study revealed that student's trusting relationship with his/her teacher motivates the student to use the teacher's written feedback in revision and eventually improving his/her draft.

\subsection{Traditional grammar / linguistic feedback}

Mckay [18] about grammatical errors believed that grammatical errors can most of the times be distinguished, and learners can be referred to a particular regularity in the language to remedy the situation: other aspects of writing such as unfamiliarity with a topic, lack of specificity, and poor organization do not offer such clear situations.

Moreover, according to Myers [17], one popular way of providing students with feedback that has been used for ages in writing classes is correcting the students' grammatical mistakes. In other words, by working on the rules of punctuation, spelling, grammar, and style of writing, traditional grammar feedback supplies corrections in a straightforward manner as feedback for sentence level or form-based errors. However, this kind of feedback might create some negative attitudes among the students.

\subsection{Auditory feedback}

According to Richards et al. [20]:

When people speak, they can hear what they are saying, and can use this information to monitor their speech and to correct any mistakes. This is called auditory feedback. For example in the following utterance the speaker uses auditory feedback to correct his/her pronunciation:

- Would you like a cup of tea or coffee; I mean tea or coffee. 


\subsection{Delayed Auditory feedback}

Delayed Auditory feedback is a technique which can show how language speakers depend on auditory feedback, for example hearing what they have just said (when speaking). In studies of delayed auditory feedback, speakers wear earphones through which they hear what they have just said, but after a short delay the effect of this on speakers is that it is very difficult for them to speak normally (Richards et al. [20]).

\subsection{Kinaesthetic feedback}

In speaking or writing the feedback we receive comes from the movement and position of the muscles, organs, etc., and it is used to produce speech or writing. In addition, the ability to feel where our tongues are in the mouth, for example, is a significant factor in being able to speak clearly. If this kinaesthetic feedback is interfered with, for example as a result of a dental injection, which causes he tongue to lose sensation, our speech may become slurred. The other kind of feedback that is used to monitor our communication is auditory feedback (Richards et al. [20]).

\section{METHODOLOGY}

In this study, the researchers' subjects were 60 female students who were selected by the researchers from among 110 upper-intermediate EFL students at a private language Institute. All of the students were preparing themselves for FCE exam of Cambridge University, and their age ranged over 16 (age was neglected in this study, and the students were mostly between 16 to 25). The 60 female students were then divided into two groups of 30 , one referred to as experimental and the other as the control group. The groups were randomly selected from among several classes, and they were almost at the same level of language proficiency.

\subsection{Procedure}

A standard TOEFL test (1996) was administered under testing conditions. The evaluation of the TOEFL test was absolutely objective, because each item had only one correct response.

The total number of 60 subjects whose standard deviations were between $-1<\mathrm{SD}<+1$ were selected among 110 students. The subjects were randomly divided into two groups, one group was considered as the control and the other as the experimental group. The researchers administered a writing test as pre-test in order to measure the students' writing ability. The students were given 80 minutes to write on a topic in 150 to 200 words (the students were to select a topic from among the four given topics all of which were descriptive, i.e., the students were asked whether to describe a place, a situation or an attribute, a person, or an object). Their written compositions were scored by three experienced teachers according to Farhady, Jafarpoor, and Birjandi's [14] table of Composition Grading Scale.

After selecting two almost homogeneous groups of students via both the students' proficiency level and writing skills, the same instructor taught the students of both classes. During the term, the teacher assigned some writing tasks to be done at home. Every session the students' homework assignments were collected and checked by the teacher. The teacher provided the students with feedback in both groups, i.e., every session the students were given the corrected paper of the session before. The feedback given by the teacher in both groups was traditional grammar feedback, i.e., correcting the students' writings according to formal aspects of language, e.g., grammar, structure, spelling, punctuation, and if necessary style, but in the experimental group, in addition to traditional grammar feedback, the students were given response and comments, e.g., "excellent," "I enjoyed a lot", "you have/haven't brought logical reasons for ....", "It's/it's not impossible to write better than this", and some other comments that could represent the feeling and opinion of the teacher about the students' compositions. Teachers' comments, on the other hand, let the students know how much they had fulfilled the teachers' expectations and also how much the students had improved their writing skills compared with their previous ones. At the end of the course, the same topics were given to the students to write on. The same three raters chosen to score the students' writing pre-test again scored their written compositions according to the same table of Composition Grading Scale.

The researchers also ranked the students' scores, and several data analyses were carried out to find out the difference between the students' scores in the post-test.

Having collected the required data based on the students' scores of writing pre- and post-tests, the 
researchers started analyzing the data to find out the difference between the students' scores in the post-test.

Any change in the experimental group's achievement was considered as the impact of teacher's feedback and comments, because every variable was almost equalized in the two groups except the teachers' comments on the students' writings.

\section{CONCLUSION}

\subsection{The findings of the beginning steps}

To measure homogeneity of two groups on the TOEFL test an F test was employed. The result showed that they were almost homogeneous.

A test of homogeneity of Variance was employed for the pre-test of writing skills, and the results showed that the two experimental and control groups had no significant difference in their writing abilities at the beginning of the term. The writing tests (the compositions) were scored. In order to estimate the degree of relationship among the scores given by the raters, a correlation coefficient analysis was carried out, and the results showed that the scores were highly reliable. During the term the students were provided by feedback and comments in experimental group while in control group just feedback was given to the students. At the end of the term the same writing exam was administered and the results were subjected to a One-way Analysis of Variance (ANOVA).

\subsection{The findings of the final steps}

Taking the null hypothesis into account a One-way Analysis of Variance (ANOVA) was carried out, and the obtained results demonstrated that the subjects who were provided with traditional grammar feedback along with teacher's comments had statistically significant difference in writing ability $\left(\mathrm{F}_{2,116}\right.$ : 9.62, Sig.: .000) so the null hypothesis was rejected (Table 1).

\begin{tabular}{|cccccc|}
\hline \multicolumn{7}{|c|}{ Table 1: One-way ANOVA results } \\
\hline & Sum of Squares & Df & $\begin{array}{c}\text { Mean } \\
\text { Square }\end{array}$ & $F$ & Sig. \\
\hline Between Groups & 2882.867 & 3 & 960.956 & 9.628 & .000 \\
\hline Within Groups & 11578.333 & 116 & 99.813 & & \\
\hline Total & 14461.200 & 119 & & \\
\hline
\end{tabular}

The one-way Analysis of the Variance (ANOVA) compared the pre-test and post-test of each group individually. The results showed that the students' writing skills had enhanced in both groups (Figure 1). So it was concluded that teachers' feedback and comments on the students' compositions had significant impact on students' writing improvement. Also the students were highly motivated to produce a bulk of new structures, and this was considered as fluency in writing skills. Moreover, because the students were certain that the teacher pays attention to the way they develop the topic, they did their best to support their ideas more idealistically and efficiently. On the other hand, the students were motivated to write creatively. 


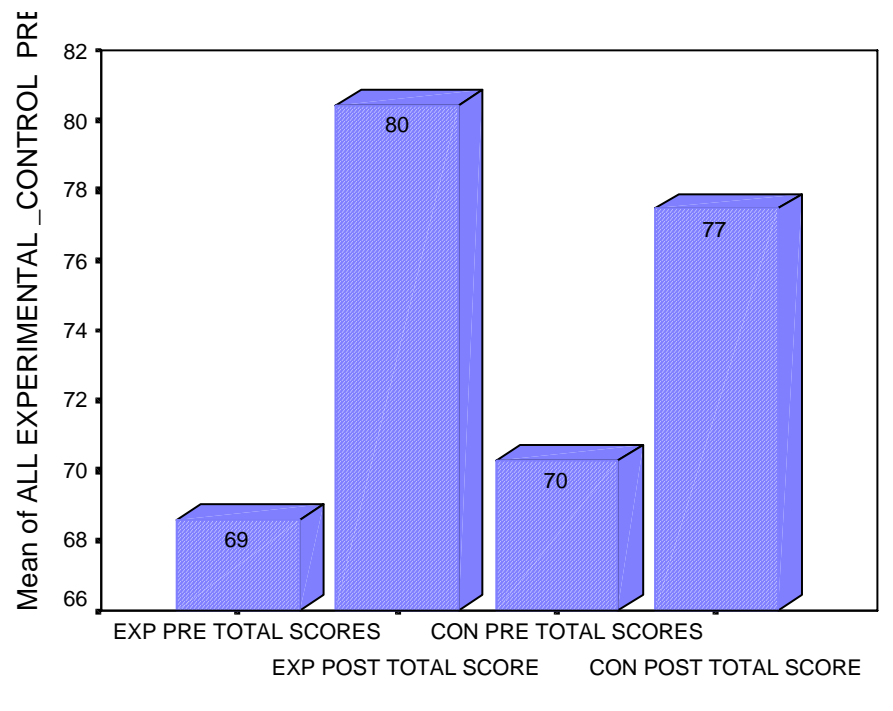

FACT_ALL TOTAL SCORES

Figure 1: Mean scores of Experimental and Control groups on writing pre-test and post-test

They had the tendency to get help of their fantasy world and write fantasy stories besides their assigned homework. The students were gradually motivated to write more paragraphs, essays, and even sometimes stories, because their teacher assured them that she was going to read their writings eagerly. One outcome of giving feedback and comments on the students' writings, based on the teacher's reports, was that the quantity of the students' writings gradually increased. During the term the students in experimental group had the tendency to write more and longer paragraphs and essays, which can be helpful to improve their writing abilities. In other words, massive writing was inadvertently reinforced, because the teachers' feedback and comments played the role of stimuli which reinforced the students' zestful attitude towards writing. Richards \& Rogers [21] who have highlighted several hypotheses as obvious implications for language teaching, believe that in order to lessen the affective filter, student work should center on meaningful communication rather than on form; input should be interesting and so contribute to a relaxed classroom atmosphere.

The results of this study accomplished the notion, proposed by Chastain [8], that "teachers also have both negative and positive affective characteristics with which to contend." It can be concluded that teachers have in their minds the students' resources and readiness as one of the principal issues facing second-language teaching. On the other hand, "teachers should be sensitive to students' need for positive, clear, and productive feedback from the teacher and other students. Also, they should divide that feedback into three groups in order of importance: (1) affective, (2) communicative, and (3) linguistic feedback (Hammerly, 1982 quoted by Chastain [8]). This order is important if they want to place feelings, meanings, and grammar in their proper perspective."

Chastain [8] also asserted, "the type of feedback language authors and teachers provide students reflects their view of language and their objectives" (p. 283).

Arriving at this objective, EFL teachers should first lead the students to focus on the content rather than form. They can not only correct the students' errors but also can comment on the content of the students' writings. Of course selecting the most proper comments represents the teachers' expertise on their writing instruction.

\subsection{Conclusion}

In this study the researchers tried to examine the effect of teachers' comments and feedback on the Iranian EFL students' writing skills. The proposal made in this study is based on the assumption that the comments the teachers give to show their opinion, viewpoints and whatever that is on their mind can play an important role in encouraging the students to make use of their suggestions and improve their writings. When students find out that a reader who not only corrects their sentences and written compositions but also takes care of the content and the way they develop an idea, they do their best to concentrate and think deeply about the topic. Furthermore, based on the reports given by the teachers, the students' negative attitude toward writing perceived as a boring, difficult, time 
consuming, and unimportant task gradually will lead toward positivistic, as every session the students count to read the comments of their teacher.

On the other hand, providing the students with feedback and comments helps them to think of new ways for developing an idea. Students do not refer to writing as a set of joined words that are set in a way to attract the teacher's attention that the assigned homework has been done; however, they refer to writing as a means of communication via which they can share their viewpoints about a topic with a skilful reader who is more experienced and can help the students to improve their writing skills by means of better thought to develop the content.

\section{REFERENCES}

[1] Brown, H. D. (2004). Language Assessment: Principles and Classroom Practices. New York: Pearson Education Inc.

[2] Raimes, A. (1991). Out of the woods: emerging traditions in the teaching of writing. TESOL quarterly, 25(3), 407-430

[3] Ryan, K. \& Cooper, J. M. (1998). Those who can, teach. Boston: Houghton Mifflin Company.

[4] Vigil, N. A. \& Oller, J. W. (1976). Rule Fossilization: A tentative model [Electronic version]. Language Learning, 26, 281-295.

[5] Nunan, D. (1991). Language teaching methodology. London: Prentice Hall International (UK) Ltd.

[6] Lewis, M. (1999). How to study foreign languages. London: Macmillan Press Ltd.

[7] Bowen, J. D., Madson, H, \& Hilferty, A. (1985). TESOL: Techniques and procedures. Rowley; Newbury House Publishers.

[8] Chastain, K. (1988). Developing second language skills: Theory and practice. San Diego: Harcourt Brace Jovanovich.

[9] Luria, A. R. (1970). Traumatic Aphasia: Its Syndromes, Psychology and Treatment. London: Humanities Press.

[10] Coltheart, M. (1987), 'Functional architecture of the language-processing system', in M. Coltheart, G. Sartori, and R. Job (eds), The Cognitive Neuro-psychology of Language. London andHillsdale, NJ, Lawrence Erlbaum Associates, pp. 1-25.

[11] Ellis, A. W. (1982). 'Spelling and writing (and reading and speaking)', in A. W. Ellis (ed). Normality and Pathology in Cognitive Functions. London: Academic Press, pp. 113-46.

[12] Raimes, A. (1983). Techniques in teaching writing. New York: Oxford University Press.

[13] Nathan, B. J. (1998). Comments on Tony Silva's on the ethical treatment of ESL writers.TESOL Quarterly, 32, 338-351.

[14] Farhady, H., Jafarpoor, A. \& Birjandi, P. (1996). Testing language skills: From theory to practice. Tehran: SAMT.

[15] Mantello, M (1997). Error correction in the L2 classroom [Electronic version]. Canadian Modern Language Review, 54(1), 1-4

[16] Mckay, S. (1984). Composing in a second language. Massachusetts: Newbury House Publishers.

[17] Myers, S. (1997). Teaching Writing as a Process and Teaching Sentence-Level Syntax: Reformulation as ESL Composition Feedback [Electronic version]. TESL-EJ, 2(4), 1-13.

[18] Conrad, S. M. and Goldstein, L. M. (1999). ESL Student Revision after TeacherWrittenComments: Texts, Contexts, and Individuals. JOURNAL OF SECOND LANGUAGE WRITING, 8(2), 147-179. 
[19] Lee, G. and Schallert, D. L. (2008). Meeting in the margins: Effects of the teacher-student relationship on revision processes of EFL college students taking a composition course. Journal of Second Language writing 17, 165-182.

[20] Richard, J. C., Platt, J. \& Platt, H. (1992). Dictionary of language teaching and applied linguistics. London: Longman.

[21] Richards, J., \& Rodgers, T. S. (2001). Approaches and methods in language teaching: A description and analysis (2nd ed.). New York: Cambridge University Press. 